\title{
Dynamic Binding and the E-Type Strategy: Evidence from Japanese
}

\author{
Takeo Kurafuji \\ Rutgers University/University of the Ryukyus
}

\section{Introduction}

This paper focuses on differences in distribution between Japanese overt and zero pronouns in donkey anaphora contexts. It will be shown that the difference in distribution is due to differences between them with respect to the strategies available for anaphora resolution. In particular, I will argue that overt pronouns in such contexts must be dynamically bound while zero pronouns may be dynamically bound or be interpreted via the E-type strategy. This shows that both strategies must be available in natural language. ${ }^{1}$ The particular distribution of Japanese overt pronouns further argues for the claim made by Chierchia 1992, 1995a about the contexts that separate the two strategies.

Section 2 will be concerned with establishing this basic claim. In section 3 and 4, I will take up two cases that appear problematic for this view and show that once some language particular facts are brought into the picture, they follow from the claims made in section 2. Conclusion will be given in section 5 .

\section{The Two Strategies and Japanese Pronouns}

In this section, I will show the basic facts which motivate the distinction I want to make between overt and zero pronouns with respect to strategies for anaphora resolution. Examples given in (1)-(3) are cases where either overt or zero pronouns can be used. (1) is narrative sequence in which the antecedent of the overt pronoun sore or the zero pronoun is a bare NP in the first sentence. (2) is an example of a conditional.

(1) Narrative sequence case

Mary-wa kuruma $a_{i}-o$ mot-tei-ru. Sor $\mathrm{i}_{\mathrm{i}}-\mathrm{wa} / \boldsymbol{\emptyset}_{\mathrm{i}}$ shako-ni a-ru.

-Top car-Acc own-Prog-Pres it-Top garage-in be-Pres

'Mary has a cari. It $t_{i}$ 's in the garage.'

(2) Conditional sentence

John-wa hon ${ }_{i}$-o ka-eba, $\quad$ sore $\mathrm{i}_{\mathrm{i}-\mathrm{o}} / \boldsymbol{\emptyset}_{\mathrm{i}}$ yom-u.

-Top book-Acc buy-Cond it-Acc read-Pres

'As for John, if he buys a book $k_{i}$, he reads it $i_{i}$.'

As is well-known, two approaches have been proposed for the anaphoric links in these examples. One is dynamic binding where the existential associated with the antecedent is assumed to extend its scope beyond a sentence boundary, and the 
other is the E-type strategy where the pronoun is analyzed as a definite description linked to the referent of the indefintie. ${ }^{2}$ These two approaches work well in these cases.

In (3), we have a symmetrical case where the E-type strategy has been argued to be inadequate (see Kratzer 1995 and the references therein for the detail). The fact that overt and zero pronouns are both acceptable here therefore shows that dynamic binding can be used for interpreting both types of pronouns.

$$
\begin{aligned}
& \text { Conditional sentence with symmetric interpretation } \\
& \text { Gyangu }_{\mathrm{i}} \text {-ga betsuno gyangu } \mathrm{j}_{\mathrm{j}} \text {-to surechiga-u-to, } \\
& \text { gangster-Nom another gangster-with pass.by-Pres-Cond }
\end{aligned}
$$

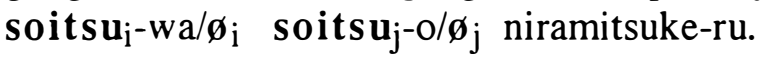

$$
\begin{aligned}
& \text { he-Top he-Acc glare.at-Pres } \\
& \text { 'When a gangsteri passes by another gangster }{ }_{j} \text {, he }{ }_{i} \text { glares at him. }
\end{aligned}
$$

Let us turn now to the examples in (4)-(6) and see why only zero pronouns can be interpreted via the E-type strategy. Although the judgments for overt pronouns vary from speaker to speaker, the zero pronoun is fully acceptable for all in these contexts. Even for those who allow overt pronouns, there seems to be a general tendency that the zero pronoun is preferred. These data call for an explanation. Now, we know that these are contexts where dynamic binding does not apply straightforwardly: (4) is a narrative sequence case in which the intended antecedent is universally quantified: (5) is a paycheck sentence where the intended antecedent is in the scope of a non-c-commanding universal. (6) is a bathroom sentence in which the antecedent is in the scope of negation. In fact, these are all the contexts in which Chierchia claims the E-type strategy comes into play. ${ }^{3}$

(4) Narrative sequence case

Dono seehini-mo chuuibukaku kensas-are-ta.

which product- $\forall$ carefully inspect-Pass-Past

Soshite $\emptyset_{\mathrm{i}} /$ ??sor $\mathrm{e}_{\mathrm{i}-\mathrm{wa}}$ hako-ni tsumer-are-ta.

and it-Top box-in pack-Pass-Past

'Every product was inspected carefully. And they were packed in the box.'

(5) Paycheck sentence

John igai-no dare-mo-ga jibun-no kurejittokaado $\mathrm{i}_{-} \mathrm{o}$ tsuma-ni except-Gen who- $\forall$-Nom self-Gen credit.card-Acc wife-to

watashi-ta. John-wa $\emptyset_{\mathrm{i}} /$ ??sor $\mathbf{e}_{\mathrm{i}}-\mathbf{o}$ aijin-ni watashi-ta.

give-Past -Top it-Acc mistress give-Past

'Everyone but John gave a credit card ${ }_{i}$ of his to his wife. John gave one $e_{i}$ of his to his mistress.' 


\author{
Bathroom sentence \\ Kono tatemono-ni toire $\mathrm{i}$-ga na-i ka, $\boldsymbol{\emptyset}_{\mathrm{i}} /$ ?? sor $\mathbf{e}_{\mathrm{i}}$-ga \\ this building-in bathroom-Nom Neg-Pres or it-Nom \\ henna tokoro-ni a-ru ka-no dochiraka-dea-ru. \\ funny place-in exist-Pres or-Cop which-Q Cop-Pres \\ 'It is the case either that this building does not have a bathroom $\mathrm{i}_{\mathrm{i}}$ or that $\mathrm{it}_{\mathrm{i}}$ is \\ in a funny place.'
}

The distributional difference we have observed in (1)-(6) is accounted for by adopting the view that there are two strategies for anaphora resolution, and in Japanese only zero pronouns can avail themselves of the E-type strategy.

It may be worthwhile at this point to consider briefly an alternative account of the problematic contexts where the difference is not due to differences in strategies for anaphora resolution but due to the availability of accommodating the antecedent in an accessible position in the structure. This can be illustrated with Roberts' 1989 account for the bathroom cases, given in (7)-(8). In her account, the pronoun in the second disjunct in (7) is actually bound by the indefinite NP in the accommodated antecedent clause of the conditional, underlined in (8).

(7) This building does not have a bathroom or it is in a funny place.

This building does not have a bathroom or if this building has a bathroom $\mathrm{it}_{\mathrm{i}}$ is in a funny place.

But now consider the Japanese bathroom sentence in (9) where such an accommodation is made explicit.

$$
\begin{aligned}
& \text { Kono tatemono-ni toire }{ }_{i} \text {-ga na-i ka, } \\
& \text { this building-in bathroom-Nom Neg-Pres or } \\
& \text { moshi } g_{j} / *^{*} \text { or } e_{i}=\text { ga/toire }{ }_{i} \text { ga a-ru-nara, } \\
& \text { if it-Nom bathroom-Nom exist-Pres-Cond } \\
& \emptyset_{\mathrm{i}} / \text { sor }_{\mathrm{i}} \text {-ga henna tokoro-ni a-ru ka-no dochira-ka dea-ru. } \\
& \text { it-Nom funny place-in exist-Pres or-Cop which-Q Cop-Pres } \\
& \text { 'It is the case either that there is not a bathroomi or that if there is a } \\
& \text { bathroom, } i_{i} \text { is in a funny place.' }
\end{aligned}
$$

The important point to note in (9) is that the overt pronoun in the second disjunct is now grammatical, and there is no preference between the overt and zero pronouns. The contrast between (6) and (9) with respect to the availability of overt pronouns in the second disjuncts is important. If the accommodation approach à la Roberts were correct, it would be predicted that there be no difference between (6) and (9) since (6) in fact has the representation in (9) and the overt pronoun in (6) should be OK like the one in (9). But this prediction is not borne out. The contrast between (6) and (9) suggests that accommodation doesn't take place to interpret the pronouns in bathroom sentences. They can be interpreted in a different way, namely the E-type strategy. 
There is another aspect of the example in (9) that is worth noting. While the difference between overt and zero pronouns is neutralized in the consequent, interestingly enough, it shows up in the antecedent of the conditional. The zero pronoun and the full bare noun phrase are acceptable while the overt pronoun is not allowed here. The impossibility of the overt pronoun follows staightforwardly from our claim. Overt pronouns are variables to be dynamically bound, but in bathroom sentences, the intended antecedent is in the scope of negation. So, the overt pronoun in the antecedent of the conditional is not interpretable.

I therefore conclude that the correct explanation for the distribution of overt and zero pronouns must be given in terms of strategies they may avail themselves of rather than general principles governing accommodation of antecedent.

Before concluding this section, I would like to briefly discuss a fact about the interpretation of the zero pronouns in narrative sequence cases that also shows that our claim is on the right track. When we consider (4), repeated as (10), we see that in fact it is only acceptable under a plural interpretation for the zero pronoun. ${ }^{4}$

(10) Narrative sequence case

Dono seehini-mo chuuibukaku kensas-are-ta.

which product- $\forall$ carefully inspect-Pass-Past

Soshite $\emptyset_{\mathrm{i}}$ /??sor $\mathrm{e}_{\mathrm{i}}$-wa hako-ni tsumer-are-ta.

and it-Top box-in pack-Pass-Past

'Every product was inspected carefully. And they were packed in the box.'

That is, the narrative sequence is interpreted as schematized in (11) in which we are lumping every product's being inspected into a single event, and it is not interpreted as in (12), where events are described per product.

\begin{tabular}{|c|c|c|}
\hline first event & second & vent \\
\hline $\begin{array}{ll}\text { product a } & \text {-inspected } \\
\text { product } b & \text {-inspected } \\
\text { product } c & \text {-inspected }\end{array}$ & $\begin{array}{l}\text { product a } \\
\text { product b } \\
\text { product c }\end{array}$ & $\begin{array}{l}\text {-packed } \\
\text {-packed } \\
\text {-packed }\end{array}$ \\
\hline
\end{tabular}

(12)

event 1

product a -inspected and then packed

event 2

product $\mathrm{b}$-inspected and then packed

event 3

product c -inspected and then packed 
This is analogous to the English example (13b).

a. Every $\operatorname{man}_{\mathrm{i}}$ walked in. *I saw himi.

b. Every $\operatorname{man}_{i}$ walked in. I saw them ${ }_{i}$.

If this is the case, then the contrast we see between overt and zero pronoun in (4) is parallel to the contrast between (13a) and (13b).

Two explanations of why plural pronouns may have universals as antecedents have been given in the literature. One is due to Root 1986 and Kamp and Reyle 1993 both of whom propose that plural pronouns are bound by referents abstracted from universals.

An alternative account, due to Chierchia 1992, treats the phenomenon of plural donkey anaphora in terms of the E-type strategy interacting with number marking. For the Japanese case, then, the question that arises is the following. We know that overt pronouns cannot be interpreted dynamically. We also know that the E-type strategy only applies to zero pronouns. The question we have to answer is why the E-type strategy with the zero pronouns being interpreted as singular is ruled out. An explanation for this can be given in terms of Chierchia's account of (13a) and (13b). He explains the contrast between (13a) and (13b) in terms of how the E-type strategy interacts differently with singular and plural pronouns. He represents the truth condition of 'every man walked in' as in (14), where 'o' is a Davidsonian argument.

$$
\underline{\exists} \text { o } \uparrow \forall x\left[\operatorname{man}^{\prime}(x) \rightarrow\right. \text { walk-in'(o)(x)] }
$$

The second sentences of (13) are interpreted as follows. In his approach, E-type pronouns involve functions that are most salient in contexts. In narrative sequence cases, the most salient function is a function from occasions into individuals in those occasions. So the narrative sequence in (13) is represented as in (15).

$$
\begin{aligned}
& \exists \mathrm{\exists} o \uparrow \forall \mathrm{x}\left[\mathrm{man}^{\prime}(\mathrm{x}) \rightarrow \text { walk-in' }(\mathrm{o})(\mathrm{x}) \wedge \exists \mathrm{J}^{\prime} \uparrow\left[\mathrm{saw}^{\prime}\left(\mathrm{o}^{\prime}\right)(\mathrm{f}(\mathrm{o}))(\mathrm{I})\right]\right] \\
& \mathrm{f:} \mathrm{a} \mathrm{function} \mathrm{from} \mathrm{occasions} \mathrm{into} \mathrm{groups} \mathrm{of} \mathrm{men} \mathrm{that} \mathrm{walked} \mathrm{in} \mathrm{at} \mathrm{that} \\
& \text { occasion }
\end{aligned}
$$

This means that we are lumping every man's walking-in into one single event. Therefore only when the pronouns are plural, the anaphoric link in narrative sequence cases with the universally quantified antecedents is possible as in (13b). If we go with this approach, we can maintain a general account of the distributional facts in (1)-(6), in terms of the strategies they use for anaphora resolution.

\section{Zero Pronouns and Non-Maximality}

We have seen some advantages of making the distinction between zero pronouns and overt counterparts with respect to the strategies that apply to them. Now I turn to an apparent problem posed by the view of Japanese zero pronouns as E-type. 
Under the E-type approach, both singular and plural pronouns are interpreted as denoting the maximal sum of individuals. For example, in (16) the pronoun is singular and there is a uniqueness presupposition here. So, the pronoun is interpreted as a function from individuals into their credit card. In (17), the pronoun is plural and the maxiamality is required, so that it is interpreted as a function from individuals into the credit cards they have.

(16) Everyone except John gave his credit card $i$ to his wife. John gave $i_{i}$ $(=\mathrm{f}(\mathrm{John}))$ to his mistress.

$\mathrm{f}$ : a function from individuals into their credit card

(17) Everyone but John gave his credit cards $s_{i}$ to his wife. John gave them $m_{i}$ $(=\mathrm{f}(\mathrm{J} o h n))$ to his mistress.

$\mathrm{f}$ : a function from individuals into their credit cards

For the sake of exposition, I characterize the E-type pronouns as in (18).

(18) E-type pronouns are functions from occasions into the maximal sum of individuals or functions from individuals into the maximal sum of individuals, of type $\langle e, e>$.

Now let us turn to Japanese paycheck sentences. The interpretation of the zero pronoun in Japanese paycheck sentence like (5), repeated as (19), is slightly different from its English counterpart.

Paycheck sentence

John igai-no dare-mo-ga jibun-no kurejittokaado ${ }_{i}-0$ tsuma-ni except-Gen who- $\forall$-Nom self-Gen credit.card-Acc wife-to watashi-ta. John-wa $\emptyset_{\mathrm{i}} /$ ??sor $\mathbf{e}_{\mathrm{i}}$ - $\mathbf{o}$ aijin-ni watashi-ta. give-Past -Top it-Acc mistress give-Past 'Everyone but John gave a credit card $d_{i}$ of his to his wife. John gave one $e_{i}$ of his to his mistress.'

The first sentence of (19) can be true even if every man has more than one credit card and gave only one of them to his wife. By the same token, the second sentence of (19) can be true even if John has more than one credit card and gave only one of them to his mistress. So, as shown in the translation given in (19), the sentence means: "Everyone but John gave a credit card of his to his wife. John gave one of his to his mistress." This difference between English and Japanese paycheck sentences with respect to maximality is shown in (20), where John has three credit cards a, b, and c, and he gave to his mistress a and b, but not c, and in this scenario (17) is false while (19) can be true. 
(20)

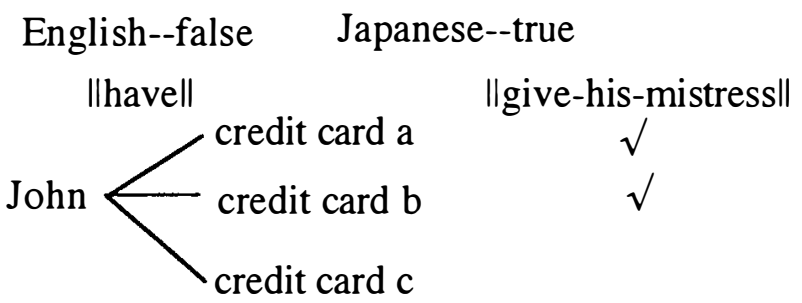

So, here is the apparent problem. What we want for the zero pronoun is the existential reading, but the E-type strategy seems to yield only the maximal sum. The question is, then, how can we get the existential readings via the E-type strategy? I will show that actually we can obtain the existential readings via the Etype strategy by assuming that Japanese bare/common nouns are kind-denoting expressions or mass-terms. As is extensively discussed by Krifka 1995 and Chierchia 1995b, 1996, common nouns in languages like Chinese and Japanese should be treated as kind-denoting expressions. For example, the object in (21) is used in a bare form and its interpretation depends on the context. I represent the kind-denoting expression as capital letters as illustrated in (21b). (21b) is read as: John read the book-kind.
a. John-ga hon-o yon-da.
-Nom book-Acc read-Past
'John read a book/books.'
b. $\operatorname{read}^{\prime}(B O O K)(j)$

Of course nobody can read kinds, so that the existential reading like 'John read a book' should be derived via a rule. Following Chierchia 1996, I assume that the Derived Kind Predication rule as given in (22) yields existential readings.

(22) Derived Kind Predication (DKP) (Chierchia 1996)

If $P$ applies to objects and $K$ denotes a kind, then

$P(\ldots, K, \ldots)=\exists x[\cup K(x) \wedge P(\ldots, x, \ldots)]$

Via the Derived Kind Predication, (21b) is represented as in (23).

$$
\begin{aligned}
& \operatorname{read}^{\prime}(B O O K)(j) \\
& =\exists x\left[\cup \operatorname{BOOK}(x) \wedge \operatorname{read}^{\prime}(x)(j)\right]
\end{aligned}
$$

Semantically, kinds correspond to the individual sums. So as shown in (24), the capital letter BOOK in a world $w$ denotes the greatest element that is a book in w.

(24) $\|\mathrm{BOOK}\|_{\mathrm{W}}$ denotes the greatest element which satisfies $\|\cup \mathrm{BOOK}\|_{\mathrm{W}}$. 
Now let us go back to zero pronouns in Japanese paycheck sentences. I propose that they are interpreted as functions from individuals into kinds, as given in (25).

(= pseudo-Japanese of the second sentence of (19))

John gave $\mathrm{f}(\mathrm{John})$ to his mistress

$\mathrm{f}$ : a function from individuals into the credit-card-kind that they have

Notice that the function in (25) is not different from the English E-type pronouns characterized in (18), for it is a function from individuals into the individual sum of type $\langle e, e>$. Via the DKP rule, (25) is represented as in (26).

$$
\begin{aligned}
& \text { give' }(j ’ s \text { mistress })(f(j))(j) \\
& =\exists x\left[\cup \operatorname{CREDIT}-\operatorname{CARD}(x) \wedge \text { have }^{\prime}(x)(j) \wedge \text { give }(j ' s \text { mistress })(x)(j)\right]
\end{aligned}
$$

(26) represents the interpretation of the second sentence of (19). That is, John doesn't have to give to his mistress all the credit cards that he has, which is represented by the existential quantification.

To sum up, zero pronouns in Japanese paycheck sentences are interpreted just like pronouns in English paycheck sentences. The interpretive differences between Japanese zero pronouns and English pronouns follow from the fact that Japanese common nouns are kind-denoting expressions.

\section{Overt Pronouns and Strong Readings}

Let us turn now to an apparent problem with the claim that overt pronouns can only be dynamically bound. Let us take a look at English (27) and its Japanese counterpart (28) which are quantificational structures involving relative clauses.

(27) Every farmer who owns a donkey beats it.

(28) [Rel Ronbun ${ }_{\mathrm{i}}$-o yon-da] dono gakusee-mo sor $\mathbf{e}_{\mathrm{i}}$ hihanshi-ta. paper-Acc read-Past which student- $\forall$ it-Acc criticize-Past 'Every student that read a paper criticized it.'

It is well-known that the English example has two readings. The strong reading is: every farmer who owns a donkey beats all the donkeys he has, and the weak reading is: every farmer who owns a donkey beats at least one donkey he has. In Chierchia's approach, the strong reading in (27) is obtained by the E-type strategy as shown in (29). In (29) the pronoun is interpreted as a function from farmers into the donkeys that they have.

(29) Strong reading: the E-type strategy

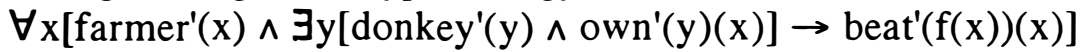

$f:$ a function from farmers into the donkeys that they own 
The Japanese example in (28) is also ambiguous between the two readings. But the fact that it has the strong reading poses a problem for our approach. The pronoun used in this example is overt, and we have claimed that overt pronouns are variables to be dynamically bound and can not be interpreted as E-type. This means the E-type strategy like (29) is not available for (28).

So, the question is: How can we get the strong reading with overt pronouns without giving up the view that overt pronouns cannot be interpreted as E-type but must be variables? My solution is that universal quantificational force is given to the overt pronoun by a necessity operator. As shown in (30), an overt adverb of quantification kanarazu, which corresponds to English always, can be used in a relative clause donkey sentence, and the strong reading with the overt pronoun is possible in (30).

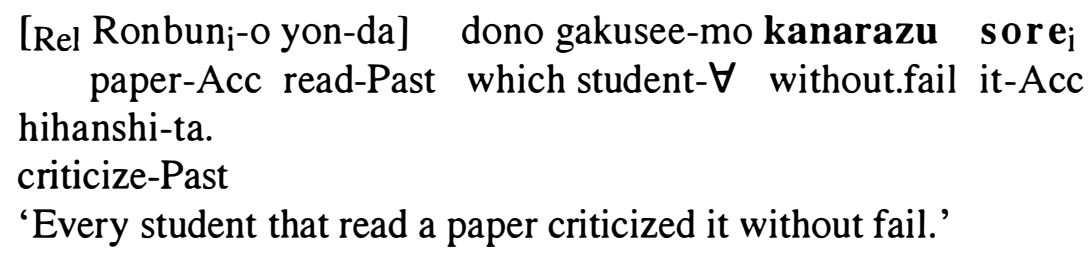

I assume that the example in (28) has an implicit necessity operator corresponding to karanazu 'always'. The relevance of adverbs of quantification is shown in (31).

[Rel Ronbun $\mathrm{i}_{\mathrm{i}}$-o yon-da] dono gakusee-mo taitee sor $\mathbf{e}_{\mathrm{i}-\mathrm{o}} / \varnothing_{\mathrm{i}}$ paper-Acc read-Past which student- $\forall$ mostly it-Acc hihanshi-ta. criticize-Past 'Every student that read a paper criticized most of the papers he read.'

This example has an adverb of quantification, taitee 'mostly' and one of the readings of the sentence is that every student that read papers criticized most of the papers that he read. 5 For the sake of concreteness, let us consider the situation described in (32). 
(32)

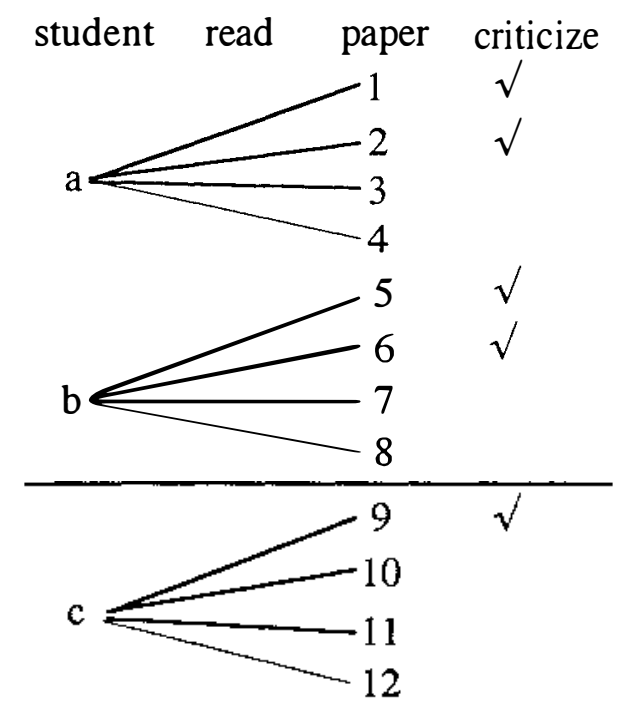

The lines between students and papers stand for the read-relation. The thin lines indicate that the read-relation does not hold. For example, student a does not read paper No.4. The check mark stands for the ciriticize-relation. So, student a reads paper 1, paper 2, paper 3, but doesn't read paper 4, and he criticizes paper 1 and paper 2, but he doesn't criticized paper 3. The example in (31) is true if the domain of students does not include student c. In other words, if there is a student like c, who reads three papers but criticizes less then half of them, (31) is false. The truth condition for (31) is represented as in (33).

$$
\forall x\left[\operatorname{student}^{\prime}(\mathrm{x}) \rightarrow \operatorname{MOSTy}\left[\operatorname{paper}^{\prime}(\mathrm{y}) \wedge \operatorname{read}^{\prime}(\mathrm{y})(\mathrm{x})\right]\left[\operatorname{criticize}^{\prime}(\mathrm{y})(\mathrm{x})\right]\right]
$$

As (33) indicates, if adverbs of quantification like mostly and the covert always can bind the pronouns in relative clause donkey sentences, then we get the relevant readings. I propose that a logical representation like (33) is derived by assuming that dono gakusee 'which student' and the universal quantificational particle -mo make a constituent and move to IP, stranding the relative clause $\mathrm{CP}$, as schematized in (34). 
(34)

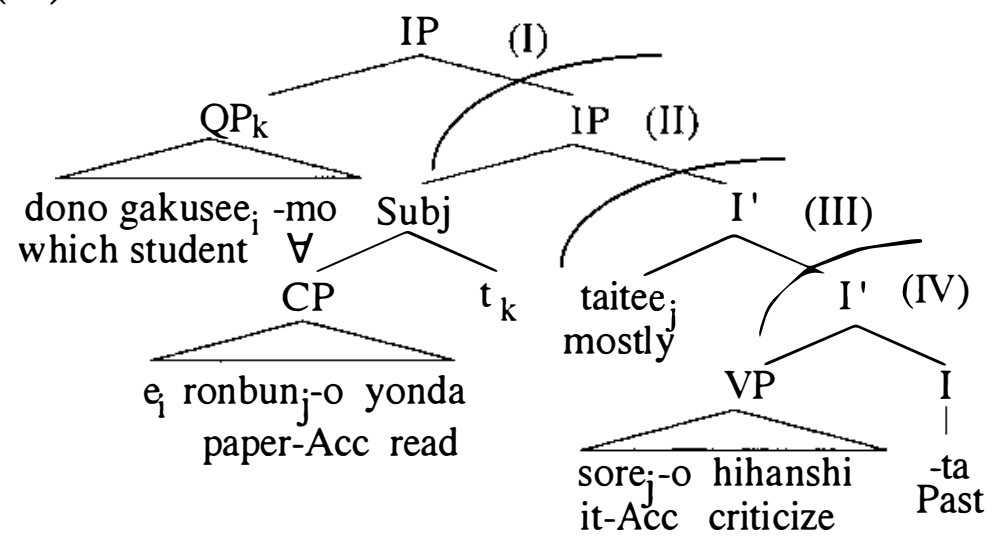

(I) Outer Quantifier (II) Restriction (III) Q-Adverb (IV) Nuclear Scope

In this structure, the stranded relative clause $\mathrm{CP}$ is interpreted as the restrictive clause and the lower I' is interpreted as nuclear scope of the adverb of quantification, and the intended reading follows.

It is worthwhile noting that English relative clause donkey sentences like (35) do not have the reading in (33).

Every student who read a paper mostly criticized it.

So, one question we might ask is why Japanese allows such a derivation while English doesn't. I propose that the difference between English and Japanese comes from the fact that English every and Japanese - mo are syntactically different from each other. I assume that (31) has the s-structure in (36).

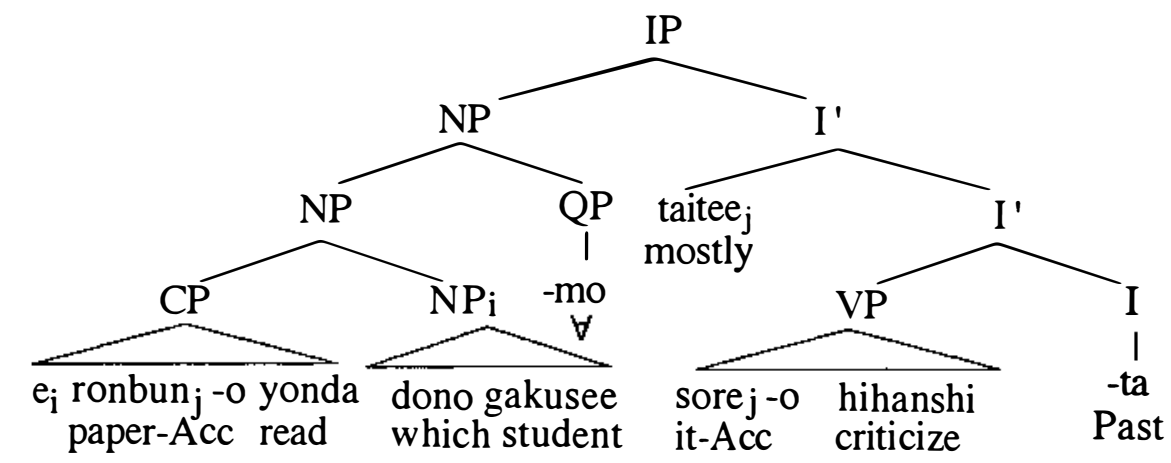

There are two crucial points to derive the LF structure in (34) from the s-structure (36). One is that the universal quantificational particle -mo adjoins to NP, not being a head of DP which takes NP as its complement. This means that we treat the quantificational particle as an adverbial element. In fact the distribution of -mo suggests that it is an adjunct element rather than a quantificational determiner. As shown in (37), it can be used with PP and IP. 
(37)
a. [PP dono kuni kara ]-mo which country from $-\forall$ 'from every country'

b. [IP dono gakusee-ga ki-te]-mo, ... which student-Nom come-inf.- $\forall$ 'no matter which student comes, ...' (cf. Nishigauchi 1990)

The other point to note is the fact that Japanese $w h$-phrases are polarity items which are licensed by - $m o$ or the Q-marker - $k a$. So I assume that the head NP moves to Spec QP to be licensed, as illustrated in (38). And then the QP undergoes QR to IP, yielding (34).

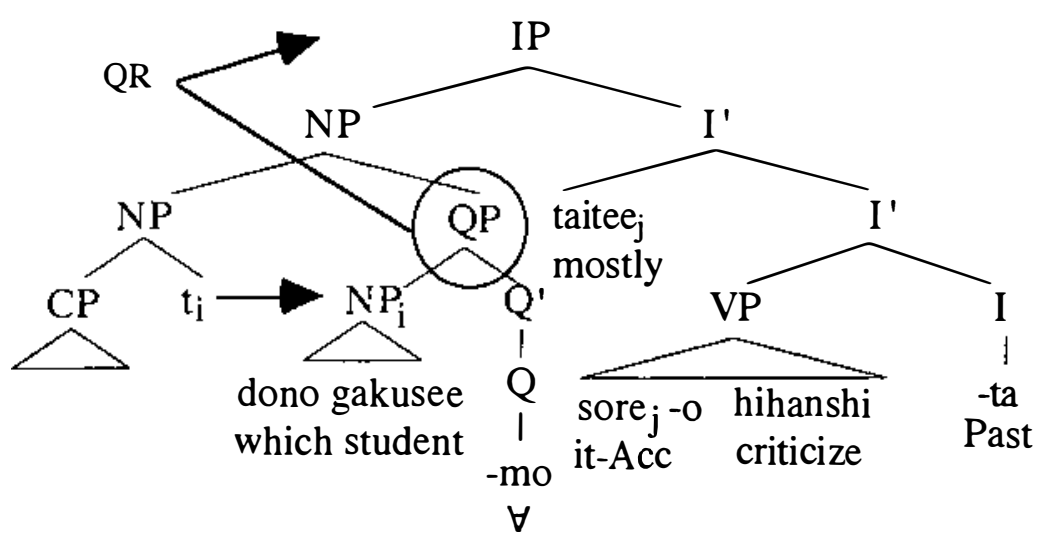

It would be obvious why English adverbs of quantification cannot bind indefinites in the relative clause in an example (39).

*Every student who read a paper mostly $_{j}$ criticized $i t_{j}$.

The story above suggests itself. In the Japanese case, the parts corresponding to every student undergo movement as a unit, stranding the relative clause. On the other hand, in English, every and student do not make a constituent, if the structure of nominals is as in (40), as originally argued by Partee 1975 and defended by Dayal 1996. 
(40)

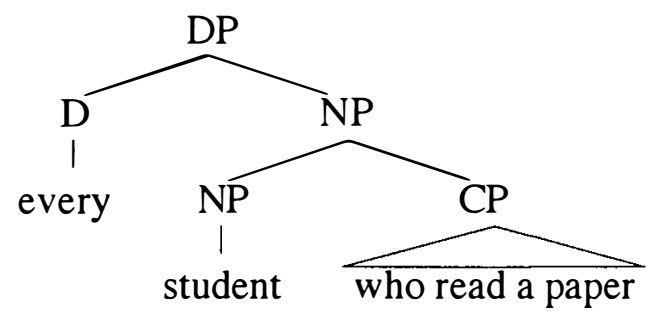

Even if student head-moves to every, still the D-N complex can't undergo QR-like movement out of the DP since it is $\mathrm{X}^{0}$. So, the difference between English and Japanese can be derived from the structural difference of quantificational noun phrases between the two languages. And we can maintain the view that overt pronouns are dynamically bound in spite of the fact that they have strong reading in the cases we have looked at.

\section{Conclusion}

To conclude, in this paper, I have shown the following facts:

(i) In Japanese narrative sequence cases with universally quantified antecedents, paycheck sentences, and bathroom sentences, overt pronouns are less acceptable.

(ii) The interpretations of zero pronouns in Japanese paycheck sentences are slightly different from those in English counterparts. English pronouns are interpreted as the maximal sum while Japanese zero pronouns are interpreted as existential.

(iii) Overt pronouns in Japanese bathroom sentences become acceptable if we explicitly use if-clauses.

(iv) In Japanese relative clause donkey sentences, the strong readings are available with either overt pronouns or zero pronouns.

The primary theoretical implication of these facts is the availability of two strategies for anaphora resolution along the lines proposed in Chierchia 1992 and 1995a. More specifically, we showed the following.

(i') In order to be interpreted as E-type, Japanese pronouns must be zero. Overt pronouns are interpreted only as variables to be dynamically bound. 6

(ii') The difference between English and Japanese described in (ii) follows from the fact that Japanese common nouns are kind-denoting expressions.

(iii') The Robertsian accommodation does not have to take place to establish anaphoric links in bathroom sentences.

(iv') Overt pronouns in Japanese donkey sentences are bound by adverbs of quantification. 


\section{Endonotes}

*This is a portion of my ongoing dissertation project. I would like to thank my thesis adviser Veneeta Dayal, and my thesis committee members Maria Bittner and Roger Schwarzchild for their insightful comments and suggestions. I am also grateful to Masaaki Fuji, Anastasia Giannakidou, Takao Gunji, Masahito Kawamori, Hiroshi Mito, Mandy Simons for providing their judgment and/or helpful suggestions. The comments from an anonymous SALT 8 referee were also very informative and beneficial.

${ }^{1}$ Kratzer 1995 and Cheng and Huang 1996 also argue that dynamic binding (or unselective binding) and the E-type strategy are both necessary in natural language. 2The notion of the E-type pronouns varies from author to author (cf. Evans 1977, Cooper 1979, Heim 1990, Neale 1990 among others). The present paper follows the notion used in Chierchia 1992, 1995a: The E-type pronouns are the most salient functions in contexts.

${ }^{3}$ Cooper 1979 and Jacobson 1992 also analyze the pronouns in paycheck sentences as E-type.

${ }^{4}$ The overt pronoun becomes acceptable if followed by a plural morpheme -ra, as shown in (i).
Dono seehini-mo chuuibukaku kensas-are-ta.
which product- $\forall$ carefully inspect-Pass-Past
Soshite sore-raj-wa hako-ni tsumer-are-ta.
and it-Pl-Top box-in pack-Pass-Past
'Every product was inspected carefully. And they were packed in the box.'

This seems problematic for our claim that overt pronouns are variables to be dynamically bound, since universal quantifier cannot extend its scope beyond a sentence boundary. To account for (i), I assume, with Kawasaki 1989, that the plural morpheme is interpreted as definite marker. The compositional semantics of sore $+-r a$ is illustrated in (ii).

(ii)

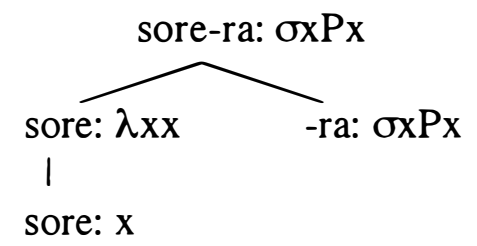

The plural morpheme is translated into oxPx, of type $e$, where $\mathrm{P}$ is a contextually salient property. The overt pronoun sore is first translated into a variable $\mathrm{x}$, and then $\lambda$-abstracted as $\lambda \mathrm{xx}$, of type $\langle e, e\rangle$, which combines with $\sigma x P x$, yielding oxPx. So, the overt pronoun is not dynamically bound but bound by the $\lambda$ operator 5 The Korean donkey sentence corresponding to (31) also has the reading described in the text. See Yoon 1994. 
6Tomioka 1997a, b and Hoji 1998 argue that Japanese zero pronouns are property anaphora (or syntactically speaking, NP anaphora under the DP analysis).

\section{References}

Cheng, Lisa L.-S. and C.-T. James Huang. 1996. Two types of donkey sentences. Natural Language Semantics 4: 121-163.

Chierchia, Gennaro. 1992. Anaphora and dynamic binding. Linguistics and Philosophy 15: 111-183.

Chierchia, Gennaro. 1995a. Dynamics of meaning: Anaphora, presupposition, and the theory of grammar. The University of Chicago Press, Chicago.

Chierchia, Gennaro. 1995b. Plurality of mass nouns and the notion of "semantic parameter". ms. University of Milan.

Chierchia, Gennaro. 1996. Reference to kinds across languages. ms. University of Milan.

Chierchia, Gennaro. 1997. Chinese conditionals and the theory of conditionals. ms. University of Milan.

Cooper, Robin. 1979. The interpretation of pronouns. In Syntax and Semantics 10, eds. F. Heny and H. Schnelle, 61-95. New York: Academic Press.

Dayal, Veneeta. 1996. Locality in wh quantification. Dordrecht: Kluwer Academic Press.

Evans, Gareth. 1977. Pronouns, quantifiers, and relative clauses. Part I. Canadian Journal of Philosophy 7: 467-536.

Heim, Irene. 1982. The semantics of definite and indefinite noun phrases. Doctoral dissertation, University of Massachusetts, Amherst.

Heim, Irene. 1990. E-type pronouns and donkey anaphora. Linguistics and Philosophy 13: 137-178.

Hoji, Hajime. 1998. Null object and sloppy identity in Japanese. Linguistic Inquiry 29: 127-152.

Jacobson, Pauline. 1992. Bach-Peters sentences in a variable-free semantics. In Paul Dekker and Martin Stokhof, eds. Proceedings of the Eighth Amsterdam Colloquium, 283-302, Institute for Language, Logic and Computation, University of Amsterdam.

Kamp, Hans and Uwe Reyle. 1993. From discourse to logic. Dordrecht: Kluwer Academic Press.

Kawasaki, Noriko. 1989. Jibun-tachi and non-coreferential anaphora. In Papers in quantification, NFS Grant BNS 8719999, Principal investigators: Emmon Bach, Angelika Kratzer and Barbara Partee, Department of Linguistics, University of Massachusetts, Amherst.

Kratzer, Angelika. 1995. Stage-level and individual-level predicates. In Gregory N. Carlson and Francis Jeffry Pelletier, eds. The generic book, The University of Chicago Press: Chicago, 125-175.

Krifka, Manfred. 1995. Common nouns: a contrastive analysis of Chinese and English. In Gregory N. Carlson and Francis Jeffry Pelletier, eds. The generic book, The University of Chicago Press: Chicago, 398-411. 
Neale, Stephan. 1990. Descriptions. Cambridge, Mass.: The MIT Press.

Nishigauchi, Taisuke. 1990. Quantification in the theory of grammar. Dortrecht: Kluwer Academic Press.

Partee, Barbara. 1975. Montague grammar and transformational grammar. Linguisitc Inquiry 6: 203-300.

Roberts, Craige. 1989. Modal subordination and pronominal anaphora in discourse. Linguistics and Philosophy 12: 683-721.

Root, Rebecca. 1986. The semantics of anaphora in discourse. Doctoral dissertation, University of Texas, Austin.

Tomioka, Satoshi. 1997a. The laziest pronouns. To appear in Japanese/Korean Linguistics7, Center for the Study of Language and Information, Stanford University, Stanford.

Tomioka, Satoshi. 1997b. Japanese noun phrases: null or otherwise. Handout given at Crosslinguistic variations in semantics, LSA Institute, July 26, 1997, at Cornell University.

Yoon, Young-Eun. 1994. Weak and strong interpretations of quantifiers and definite NPs in English and Korean. Doctoral dissertation, University of Texas, Austin. 